\title{
Transoral settotomy for Zenker diverticulum: long-term outcomes in elderly patients
}

\author{
M Rottoli, S Siboni, D Bona, I Russo, L Bonavina \\ From XXIII Annual Meeting of the Italian Society of Geriatric Surgery \\ Lecce, Italy. 2-4 December 2010
}

\section{Background}

Zenker diverticulum is often observed in elderly patients complaining of dysphagia and regurgitation. Endoscopic transoral stapling was introduced in the 90's as an alternative to standard open diverticulectomy and cricopharyngeal myotomy for the treatment of Zenker diverticulum. Aim of this study was to evaluate the results of this procedure in patients over 75 years of age.

\section{Material and methods}

Between 2002-2010, 73 patients (45 males, median age 74 years) underwent transoral stapling. The operation was performed under general anesthesia using a Weerda diverticuloscope and one or more cartridges of linear endostapler. Since 2008, a retention suture (Endostitch ${ }^{\circledR}$ ) was routinely used to improve traction of the septum inside the stapler jaws. Patients OLDER and YOUNGER than 75 years were compared for perioperative variables and long-term outcomes using Chi-squared test, Student's $t$ test and Kaplan Meier analysis with log-rank test. Recurrence was defined as a relapse of the symptoms requiring reoperation.

\section{Results}

Results are shown in Table 1. Median age of the two groups was respectively 80 (range 75-88) and 66.5 years

Table 1 Comparison of short and long-term outcomes in the two groups.

\begin{tabular}{llll}
\hline Variable & OLDER (33) & YOUNGER (40) & P value \\
\hline Median age (years) & & N (\%) or median (range) & $<0.001$ \\
Male gender & $80(75-88)$ & $66.5(45-74)$ & 0.1 \\
Median BMI $\left(\mathrm{Kg} / \mathrm{m}^{2}\right)$ & $17(51.5 \%)$ & $28(70 \%)$ & 0.9 \\
Median diverticulum size (cm) & $23.5(16-30)$ & $25(20-29)$ & 0.2 \\
Diverticulum size $<3 \mathrm{~cm}$ & $3(1-6)$ & $2.5(1-6)$ & 0.01 \\
Median operative time (min) & $8(24.2 \%)$ & $21(52.5 \%)$ & 0.2 \\
Use of Endostitch & $30(15-90)$ & $20(15-60)$ & 0.4 \\
Postoperative complication & $13(32.5 \%)$ & $14(42.4 \%)$ & 0.3 \\
Median follow-up time (months) & $1(3 \%)$ & 0 & 0.8 \\
Long-term regurgitation & $45(5-108)$ & $48.5(5-104)$ & 0.8 \\
Long-term dysphagia & $2(6.1 \%)$ & $3(7.5 \%)$ & 0.5 \\
Satisfaction rate & $2(6 \%)$ & $4(10 \%)$ & 0.8 \\
5 year recurrence rate & $27(81.8 \%)$ & $32(80 \%)$ & 0.8 \\
Median time to recurrence (months) & $11.6 \%$ & $10.2 \%$ & 0.04 \\
\hline
\end{tabular}

\footnotetext{
* Correspondence: matteo.rottoli@gmail.com

Department of General Surgery, University of Milan, Policlinico San Donato

IRCCS, San Donato Milanese, Italy
}

\section{() Biomed Central}


(range 45-74). The groups were similar regarding gender, BMI, operative technique, operative time and postoperative complication rate. Only one (3\%) postoperative complication occurred in the OLDER group (periesophageal abscess), and was treated conservatively. After a similar follow-up time (45 vs 48.5 months), the two groups had a comparable rate of patients complaining of regurgitation $(6.1 \%$ vs $7.5 \%$, $\mathrm{p}=0.8$ ) and dysphagia ( $6 \%$ vs $10 \%, \mathrm{p}=0.5)$. Satisfaction rate was $81.8 \%$ and $80 \%$, respectively $(\mathrm{p}=0.8)$. Five year recurrence rate was $11.6 \%$ in OLDER and $10.2 \%$ in YOUNGER patients $(\mathrm{p}=0.8)$. The median time of recurrence was significantly longer in OLDER patients (21 vs 9.5 months, $\mathrm{p}=0.04$ ).

\section{Conclusions}

Transoral settotomy is safe and effective even in elderly patients, with short and long-term outcomes similar to younger patients. Because of the low incidence of postoperative complications and the higher rate of longterm satisfaction, the technique should be proposed as the first approach for the treatment of Zenker diverticulum in elderly patients.

Published: 24 August 2011

doi:10.1186/1471-2318-11-S1-A54

Cite this article as: Rottoli et al.: Transoral settotomy for Zenker diverticulum: long-term outcomes in elderly patients. BMC Geriatrics 2011 11(Suppl 1):A54.
Submit your next manuscript to BioMed Central and take full advantage of:

- Convenient online submission

- Thorough peer review

- No space constraints or color figure charges

- Immediate publication on acceptance

- Inclusion in PubMed, CAS, Scopus and Google Scholar

- Research which is freely available for redistribution

Submit your manuscript at www.biomedcentral.com/submit 